\title{
THE EFFECT OF SUSTAINABILITY ON THE INFORMATION SEARCH BEHAVIOUR OF HUNGARIAN CONSUMERS THROUGH THE PRACTICE OF FOOD PURCHASING
}

\author{
J. Lehota, Á. Horváth and G. RÁcz* \\ Business Scicnce Institute, Szent István University, 2100 Gödöllő, Páter Károly str. 1. Hungary
}

(Received: 13 February 2013; accepted: 28 May 2013)

In the study we aim to model the information search behaviour of Hungarian consumers committed to sustainable consumption through the practice of food purchasing. To reach our goal we examined the logic of Grunert-Wills information search model.

In our research the information search behaviour of "Trend followers" was investigated. To reach the mentioned group, data collection was carried out by the method of quota sampling, where quotas were defined according to characteristics of value system based lifestyle segments discovered in a 2011 national representative research by us. Through the analysis one-variable statistics and contingency table analysis were carried out.

Our results prove the followings: (i) the logic of Grunert-Wills model is suitable for describing the information search behaviour of conscious consumers. (ii) Lifestyle has a highlighted effect on information search behaviour.

Keywords: sustainable consumption, information search behaviour, food purchasing, model of information search behaviour, quota sampling

The study aims to examine factors that influence food purchasing decisions of Hungarian consumer groups committed to sustainable consumption** and to model information search patterns developed as a result of sustainability trend. According to the literature, Hungarian food consumer habits have recently been influenced by several trends, such as trend of convenience, health and wellness, environmental consciousness, search for experience, ethical consumption, and time consciousness (HorvÁth et al., 2005; KIRIG \& LÜTZLER, 2007). At the same time, the idea of sustainability is totalized in the behaviour of LOHAS (Lifestyle of health and sustainability) consumers.

Results of international researches (FrENCH \& RogERs, 2005; NMI, 2009) pointed out that for consumers committed to sustainability, food information possesses a highlighted role in food purchasing decisions made based on LOHAS values, because it provides the possibility to have product attributes of trust transformed into attributes of information search (ANDERSEN, 1994). Therefore, the assumption is that the behaviour of information search that appears among members of domestic sustainable consumer segment is suitable to be modelled by defining the role of food information on the package in purchasing decisions. The examination of this process is conducted based on the logic of GRUNERT and WiLLS (2007) information search model that unifies general models of purchasing decision process with communication impact study models. The logic of the model is built on the main points as follows: search and discovery - perception - preference, interpretation and conclusions - usage.

\footnotetext{
* To whom correspondence should be addressed Phone: +36 28522000 1996; fax: +36-28/410-804; e-mail: racz.georgina@gtk.szie.hu ** In our definition sustainable consumption summarises the health, ethical, and environmental friendly consumer trends, which are characterised by LOHAS lifestyle and parallel with the goals of sustainability determined by UNEP (2001).
} 


\section{Materials and methods}

This survey is the third and final part of a research process started in 2010 and it aims to model the attitude of information search within the consumer group committed to sustainability. In order to reach this goal, data collection was carried out by the method of quota sampling between the $10^{\text {th }}$ May, 2012 and $30^{\text {th }}$ June, 2012. Quotas of regions, sex, and age were defined according to characteristics of value system based lifestyle segments discovered in a 2011 national representative research, where, according to the goals, sociodemographic characteristics of the segment "Trend followers" (domestic representatives of sustainable lifestyle) were considered.

To examine the sample in terms of lifestyle was also considered important and as a result two groups were defined, "Trend followers" and "Neutrals". The appearance of the second group provides the possibility to assess results also from the point of those consumers who are committed to sustainability and consider belonging principles in their food purchasing decisions to a less extent.

Through the analysis one-variable statistics and contingency table analysis were carried out. In the case of the second, standardized residuals were considered that showed significant relationships in the contingency table (SAJTos \& Mitev, 2007).

\section{Results and discussion}

\subsection{The assessment of information search behaviour by the relationship system of the Grunert-Wills model}

2.1.1. The relationship of search, discovery, and perception. Search for artificial additives, GMO, preservatives, and colour additives free products, furthermore, search for country of origin as well as trademark/quality certification out of all food information defined in the questionnaire are the elements that support the perception of trademarks the most. Searching for these types of information results the perception of trademarks mostly such as Quality Food from Hungary, "HÍR" (Traditions, Tastes and Regions - a special programme of Ministry of Agriculture and Rural Development to enhance the value of traditional regional food), "Minőségi Magyar Sertéshús" (Hungarian High Quality Pork), "Magyar Termék" (Hungarian Product), "Környezetbarát Termék" (Environmentally Friendly Product), and Fair Trade product. Negative relationships exist in the case of consumers who search for benefits of consumption and consumers who look at the price, meaning that $40 \%$ of the first group perceives the trademark of Quality Food from Hungary, while only 17.9\% of those who search for prices perceive the trademark of Bio Product during their food purchasing decisions.

In connection with the perception of nutritional value, the search for free of artificial additives, preservatives, or colour additives statements is the most significant (generally preferred by "Trend followers") resulting a positive impact on the perception of nutritional value information such as carbohydrate content, sugar content, total fat and fat content, saturated/unsaturated fatty acid content, dietary fibre content, and sodium content. Moreover, $75.3 \%$ of respondents who prefer food free of artificial additives were able to name specific nutritional value information, while $56.6 \%$ of them tend to remember for logos of environmentally friendly food on the package. However, the influencing role of the price is worth being examined, and it mainly shows a negative relationship analyzing the perception 
of both the food nutritional value information and logos of environmentally friendly food (generally the group of "Neutrals").

The conclusion is that according to the relationship system of GRUNERT and WILLS (2007) model, in the information search behaviour of conscious consumer groups the search for food information widely contributes to the perception of them.

2.1.2. The relationship between perception and preference elements. Examining the information search behaviour of conscious consumer groups, it seems that the perception of trademarks encourages consumers to read mostly the information that is placed on the back and on the front. Regarding the first, the influencing role of Fair Trade, Environmentally Friendly Product, and Hungarian Product logos is the most important (the last two are typical elements of "Trend follower" behaviour), while respondents who ignore trademarks in their purchasing decisions are in favour of information placed on the front to a less extent (group of "Neutrals"). In the case of those who are in favour of information placed on the back, the impact of perceiving logos of Hungarian and Environmentally Friendly Products also appears, accompanied by logos represented by Fig. 1. Moreover, similarly to the previous, those respondents are in favour of information on the back the least, who do not perceive trademarks in their food purchasing decisions.

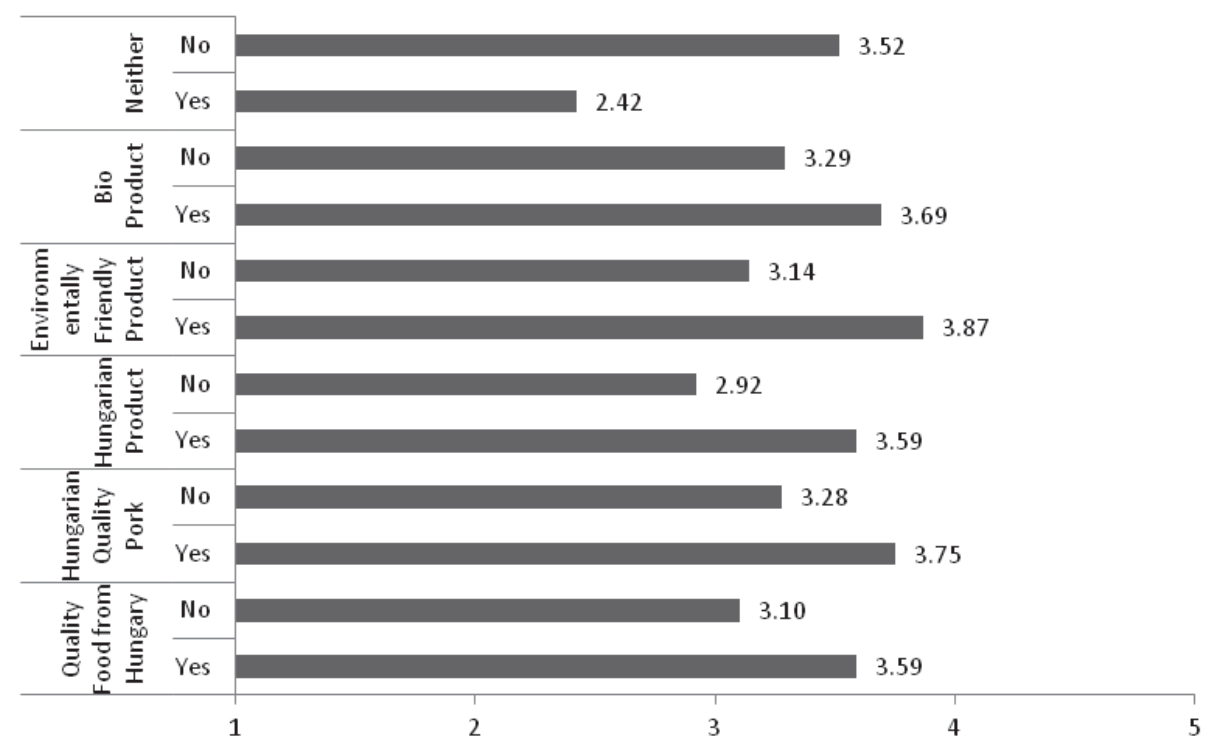

Fig. 1. The effect of perceiving trademarks on preference of information on the back of the package (2012, $\mathrm{N}=221)$

Independent sample test: $F$-test $\mathrm{P}<0.050$ - Equal variances not assumed $t$-sig $\mathrm{P}<0.050 ; F$-test $\mathrm{P}>0.050$ - Equal variances assumed $t$-sig $\mathrm{P}<0.050$

The negative impact described above appears in connection with two further elements. However, those who do not perceive trademarks rather consider being attentive to food information senseless (average: 1.84) than those who treat them highlighted (average: 1.84). 
In conscious consumer groups, trust is a highly important influencing factor of purchasing decisions. In connection with this, the perception of Bio Product trademark shows significant difference, meaning that perceivers of this trademark rather trust the complete information content of labels (average yes: 3.41; average no: 3.93).

Examining nutritional value information, the impact of perception on preference shows a greatly tighter relationship compared to the previous elements. Reading the information placed on the front and the back of the package has also a significant role in this case, and the usefulness of information and the preference of nutritional recommendations gain a higher value at the same time. The factors above are positively influenced by the perception of almost all nutritional value information (Group of "Neutrals"). In parallel with the experiences in trademarks, it is also proved here that non-perceivers of nutritional information agree with statements about preferences to a less extent, where the greatest differences appear in reading habits of food information.

All in all, in the information search behaviour researched in Grunert-Wills model, perception by conscious consumer groups obviously affects the preference of information, which appears the most strongly in factors of precise information search behaviour (e.g. examination of the front and back of the package, the usefulness of information).

2.1.3. The relationship between perception and interpretation. In connection with the interpretation of food information the most important are the effect of trademarks on chemical ingredients and saturated fatty acids. Regarding the first, perceivers of Hungarian Product, Environmentally Friendly Food (group of "Trend followers"), and Bio Product are rather able to understand chemical ingredients, while saturated fatty acids are avoided by perceivers of "Szívbarát" ("Friend of Heart"), Quality Food from Hungary, Environmentally Friendly, and Bio trademarks in a statistically proved number. The effect of perception on interpretation is strengthened further by the fact that non-users of this kind of information are less able to accurately understand chemical ingredients and values expressed per 100 grams (generally the group of "Neutrals").

Similarly to the experiences in the element of preference, also in interpretation and conclusions, the influencing effect of perception of nutritional values is the most significant and affects all model elements except for the adjunct word "reduced". Average deviations of responses coming from those who do not perceive nutritional value information prove the strong relationship between perception and interpretation in information search behaviour of conscious consumer groups.

2.1.4. The relationship between preference and usage. The examination of the relationship between preference and nutritional value information found that the priority of usefulness and reading the information on the front and back (characteristics of "Trend followers") show tight relationship in the case of those who check these kinds of labels at every purchasing occasion, while those who check the information at the time of choosing a new brand prefer short recommendations on the front of the package and nutritional recommendations, and they rather tend to read information on the back, too.

After examining the average values of those who do not use nutritional value information ("Neutrals") the result shows that a reason for this behaviour is possibly the size of fonts and numbers, because these consumers consider them to be too small (average: 4.18). However, they also believe that there is no point of checking descriptions. Furthermore, they rather think negatively about other examined factors (such as usefulness of information, nutritional 
recommendations), which shows that preference obviously influences the usage of nutritional information.

The correspondence above is also possible to be pointed out in connection with the demand for standard logos of sustainability as well as the willingness to pay a premium price. The first (placing a trademark of sustainability on the package) is in favour of those who consider information on labels useful (average: 3.81 ) and to check these signs during their purchases important (average: 1.79). For those who would pay a premium price, the role of reading information on the back is also highlighted above the two preference elements mentioned previously (average usefulness: 4.01; average senseless: 1.69), which supports to accept the possible higher price of sustainable food (average: 3.57) (characteristics of "Trend followers").

Finally, regarding the acceptance of premium price level, the influencing role of two preference elements is the most significant: reading of information on the back of the package and involving signs of bigger size in the purchasing decisions. In connection with the first, those who prefer information on the back (mainly "Trend followers") would accept a relatively high level of price increase (below $5 \%$ and between $10.1-15 \%$, Fig. 2).

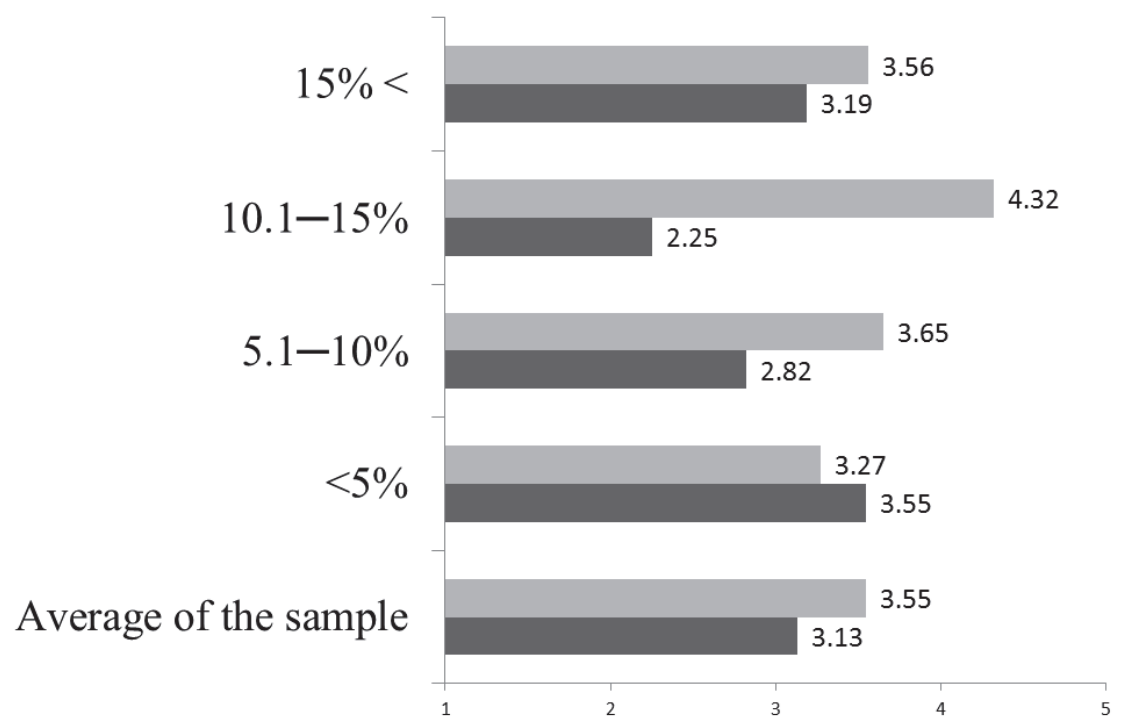

Fig. 2. The effect of preference on the level of premium price (2012, N=221). $\square$ : I check the information on back of the package before the buying decision; $\boldsymbol{\square}$ : I usually read only signs of bigger size on food packages. One-Way ANOVA $\mathrm{P}<0.05$, Test of Homogeneity of Variances $\mathrm{P}<0.05-\mathrm{Post}$ Hoc Tests Tamhane $(\mathrm{P}<0.05), \mathrm{P}>0.05$ - Post Hoc Tests LSD $(\mathrm{P}<0.05)$

Nevertheless, reading information in bigger sizes negatively affects the acceptance of price increase (below 5\%, Fig. 2).

Statements above prove that the behaviour of precise information search positively influences the usage of information, and sustainably conscious food purchasing decision reduces price sensitivity of consumers if they consider the information reliable. 
2.1.5. The relationship of interpretation, conclusions, and usage. The influencing role of interpretation and conclusions is the most significant in the case of those who check nutritional information every time or at the time of purchasing food that is considered to be healthy. The first is supported by the correct interpretation of chemical ingredients, $\mathrm{kj} / \mathrm{kcal}$ unit of measure, GDA, and unsaturated fatty acids, and respondents thought that $\mathrm{kj} / \mathrm{kcal}$ unit of measure supports the purchasing decision the most (average: 4.09) (generally the group of "Trend followers"). During purchasing healthy food, the supporting role of chemical ingredients and saturated fatty acids in the purchasing decision also appears, and in this case values expressed per pieces and the purchasing of food containing unsaturated fatty acids are highly significant. The most important here is also a quantitative factor, and respondents think that this is quantity per pieces in supporting the purchasing decision (average: 4.02).

The relationship of interpretation, conclusions, and the usage of nutritional value information do exist and it is confirmed by analysing the standard deviation of those who never use the examined labels (generally the "Neutrals"). According to this analysis respondents were never confident in the meaning of any information (such as saturated/ unsaturated fatty acids, GDA). This statement shows that for usage, the accurate interpretation of information, so that preliminary knowledge of background information is essential, otherwise the information does not or only hardly contributes to a purchasing decision following the value system.

Similarly to the experiences in the case of preference element, interpretation also influences the demand for standard logos and also the willingness to pay a premium price. In the first case, the interpretation of chemical ingredients (average: 2.92) and GDA information (average: 3.01) should be emphasized (generally the group of "Trend followers"), which means that the respondents who consider these information important would rather prefer the introduction of a standard logo for sustainability. With regard to average values the effect of GDA information is stronger. However, the value here is also around 3.00, meaning that preference has a greater role in the need for introducing logos compared to interpretation or conclusions.

In the case of willingness to pay a premium price, unsaturated fatty acids (average: 3.17), sodium and salt content (average: 4.02) show statistical relationships. Consequently, those who prefer unsaturated fatty acids (generally the group of "Trend followers") would rather buy sustainably produced food at a higher price. Finally, the analysis of model elements found out that interpretation does not affect the level of premium price paid ( $F$-test: $\mathrm{P}>0.050$ ).

\section{Conclusions}

The examination of Grunert-Wills information search model logic showed the follows: lifestyle, as it was outlined by the literature, has a defining role in the information search stage before the purchasing decision, so that consumers committed to sustainability really possess an increased demand for information and are characterized by precise product selection.

The aim of the study was to model information search behaviour of conscious consumer groups ("Trend followers"). According to our result the following conclusions can be summarised:

- Information placed on the front of the package has the most significant effect on food purchasing decisions (compare products quickly). 
- Consumers prefer standard formats, because they support purchasing decisions made according to their values (such as $\mathrm{kj} / \mathrm{kcal}$ units of measure).

- Based on the result, the conclusion is that companies producing food products (that are difficult to differentiate) are able to reach a competitive advantage by:

- practicing principles of sustainability in their operations,

- communicating the effects of the product on health, environment and society in the form of

- placing the logo on the front page of the package and conducting a communication campaign to support the introduction of the logo.

\section{References}

Andersen, E.S. (1994): The evaluation of credence goods: A transaction approach to product specification and quality control. MAPP Working paper. No. 21. The Aarhus School of Business. pp. 6-7.

French, S. \& Rogers, G. (2005): Marketplace opportunities: Growth \& demographic opportunities. Natural Marketing Institute, USA, Harleysville, pp. 7-8.

Grunert, K.G. \& Wills, J.M. (2007): A review of European research on consumer response to nutrition information on food labels. J. Public Health, 15, 385-399.

HorvÁth, Á., Fürediné, K.A. \& Fodor, M. (2005): Az értékrend hatása a táplálkozásra (The effect of values on nutrition). Hung. J. Fd, Nutr. Market., 2(1-2), 69-76.

Kirig, A. \& RüTzler, H. (2007): Food-Styles. Die wichtigsten Thesen, Trends und Typologien für die GenussMärkte. Zukunftsinstitut GmbH, Kelkheim. 130 pages.

NMI (2010): LOHAS consumers around the world. Natural Marketing Institute, LOHAS Journal. Spring. http:// www.lohas.com/sites/default/files/lohasconsumers.pdf

SAJtos, L. \& Mitev, A. (2007): SPSS kutatási és adatelemzési kézikönyv. (Handbook for SPSS research and data analysis). Alinea Kiadó. Budapest, 404 pages.

UNEP (2001): Consumption opportunities: Strategies for change: a report for decision-makers. Geneve, 73 pages. 